\title{
Hybrid models for hardware-in-the-loop simulation of hydraulic systems Part 2: experiments
}

\author{
J A Ferreira ${ }^{1 *}$, F Gomes Almeida ${ }^{2}$, M R Quintas ${ }^{2}$ and $\mathbf{J}$ P Estima de Oliveira $^{3}$ \\ ${ }^{1}$ Department of Mechanical Engineering, University of Aveiro, Aveiro, Portugal \\ ${ }^{2}$ IDMEC-Polo FEUP, University of Porto, Porto, Portugal \\ ${ }^{3}$ Department of Electronic Engineering, University of Aveiro/IEETA, Aveiro, Portugal
}

\begin{abstract}
The use of new control schemes for hydraulic systems has been the object of study during the last few years. A simulated environment is the cheapest and fastest way of evaluating the relative merits of different control schemes for a given application. Real-time simulation allows parametrization and test of the performance of real controllers. This paper describes the set-up of a real-time simulation platform to perform hardware-in-the-loop simulation experiments with the hydraulic models proposed in the companion paper (Part 1). A set of parametrization techniques are proposed for the semiempirical models of a valve-controlled hydraulic cylinder. Manufacturer's data sheets and/or experimental measurements were used to adjust the model parameters. Some of these were directly calculated and others were estimated through the use of optimization techniques. Closed-loop control experiments were then performed on the real-time simulation platform and on the real system, in order to evaluate the real-time performance of the developed models.
\end{abstract}

Keywords: fluid power, modelling, real-time simulation, hardware-in-the-loop simulation

\section{NOTATION}

$A_{\mathrm{s} 1}, A_{\mathrm{s} 2} A_{1 \mathrm{t}}, A_{2 \mathrm{t}}$

$A_{1}, A_{2}$

$f_{n}, \omega_{n}$

$F_{\mathrm{f}}$

$F_{\mathrm{L}}$

$\hat{F}_{\text {COn }}, \hat{F}_{\text {COp }}$

$\hat{F}_{\text {Sn }}, \hat{F}_{\text {Sp }}$

$g$

$g_{\text {lkc }}$

$k_{1}, k_{2}, k_{3}, k_{4}, k_{5}$

$k_{1 \mathrm{t}}, k_{2 \mathrm{t}}, k_{3 \mathrm{t}}, k_{4 \mathrm{t}}, k_{5 \mathrm{t}}$

$\bar{K}_{\mathrm{p} 0}$ pseudo-sections

cylinder chamber areas

natural (angular) frequency

frictional force

load applied force

estimated Coulomb frictional

forces for negative and positive

velocities respectively

estimated Stribeck friction for

negative and positive velocities

respectively

acceleration due to gravity

cylinder leakage conductance

pseudo-section parameters

pseudo-section parameters

relative pressure gain at $\bar{x}_{\mathrm{s}}=0$

The MS was received on 20 February 2004 and was accepted after revision for publication on 25 May 2004.

* Corresponding author: Department of Mechanical Engineering, University of Aveiro, Campo Universitario, Aveiro 3810, Portugal. E-mail: jaff@mec.ua.pt

I03504 C IMechE 2004

$$
\bar{K}_{\mathrm{q} 0}, \hat{K}_{\mathrm{vp}}
$$

$L$

$L_{v}, L_{a}$

$M$

$P_{i}$

$P_{\mathrm{L}}$

$P_{\mathrm{n}}$

$P_{1}, P_{2}$

$\bar{P}_{\mathrm{L}}$

$q_{i j}$

$q_{1 \mathrm{k}}$

$q_{\mathrm{lkc}}$

$q_{1 \mathrm{k} 0}$

$Q_{\mathrm{L}}$

$Q_{\mathrm{n}}$ flow gain at $\bar{x}_{\mathrm{s}}=0$

estimated viscous friction coefficients for negative and positive velocities respectively cylinder maximum stroke spool velocity and acceleration limits respectively connected mass (load, piston and rod)

relative pressure at valve port $i$ load pressure drop nominal pressure drop cylinder chamber relative pressures relative load pressure drop volumetric flowrate from port $i$ to port $j$ leakage volumetric flowrate cylinder leakage volumetric flowrate leakage flow at $x_{\mathrm{s}}=0$ load volumetric flowrate nominal volumetric flowrate 


\begin{tabular}{|c|c|}
\hline$Q_{\mathrm{s}}, Q_{\mathrm{t}}$ & tank and source volumetric \\
\hline$Q_{1}, Q_{2}$ & $\begin{array}{l}\text { volumetric flowrates of outlet } \\
\text { ports }\end{array}$ \\
\hline $\bar{u}$ & normalized valve input $\in[-1,1]$ \\
\hline$v_{\mathrm{p}}$ & piston velocity \\
\hline & Stribeck velocity \\
\hline$\hat{v}_{\mathrm{Sn}}, \hat{v}_{\mathrm{Sp}}$ & $\begin{array}{l}\text { estimated Stribeck velocities for } \\
\text { negative and positive velocities } \\
\text { respectively }\end{array}$ \\
\hline$V_{\mathrm{L} 1}, V_{\mathrm{L} 2}$ & $\begin{array}{l}\text { enclosed volumes at lines } 1 \text { and } \\
2 \text { respectively }\end{array}$ \\
\hline$x_{\mathrm{p}}$ & piston position \\
\hline $\bar{x}_{\mathrm{s}}$ & $\begin{array}{l}\text { normalized valve spool position } \\
\in[-1,1]\end{array}$ \\
\hline$z$ & seal deformation (friction model) \\
\hline$\beta$ & oil bulk modulus \\
\hline$\beta_{\mathrm{e} 1}$ & $\begin{array}{l}\text { effective bulk modulus for } \\
\text { chamber } 1\end{array}$ \\
\hline$\beta_{\mathrm{e} 2}$ & $\begin{array}{l}\text { effective bulk modulus for } \\
\text { chamber } 2\end{array}$ \\
\hline$\Delta P_{i j}$ & $\begin{array}{l}\text { pressure drop between port } i \text { and } \\
\text { port } j\end{array}$ \\
\hline$\Delta P_{\mathrm{m}}$ & $\begin{array}{l}\text { pressure difference to the middle } \\
\text { point }\end{array}$ \\
\hline$\xi$ & damping ratio \\
\hline$\sigma_{0}$ & seal stiffness (friction model) \\
\hline$\sigma_{1}$ & $\begin{array}{l}\text { seal damping coefficient (friction } \\
\text { model) }\end{array}$ \\
\hline
\end{tabular}

\section{INTRODUCTION}

The use of new control schemes for hydraulic systems has been the object of study during the last few years [1]. It is commonly accepted that a simulated environment is the cheapest and fastest way for the evaluation of the relative merits of different control schemes for a given application. Modelling and real-time simulation of complex systems still are, according to Burrows [2], areas to explore. In fact, and as stated by Lennevi et al. [3], with the growing computing power, more and more complex systems can be simulated in real time, with decreasing costs.

Hardware-in-the-loop simulation (HILS) refers to a technology in which some of the components of a pure simulation are replaced with the respective hardware components. This type of procedure is useful, for example, to test a controller which, instead of being connected to the real equipment under control, is connected to a real-time simulator. The controller must 'think' that it is working with the real system and so the accuracy of the simulation and its electrical interfacing to the controller must be adequate. This technology provides a mean for testing control systems over the full range of operating conditions, including failure modes. Testing a control system prior to its use in a real plant can reduce the cost and the development cycle of the overall system. HILS has been used with success in the aerospace industry and is now emerging as a technique for testing electronic control units $[4,5]$. This procedure has been applied to solve some specific problems but is seldom used as a platform to test the real-time behaviour of hardware components. The implementation of HILS is important for the performance analysis of components or systems, and also for control algorithm validation. The real-time code should be generated through model descriptions. This code can be executed afterwards in dedicated hardware, in order to guarantee enough performance for real-time execution.

The following section presents the hardware set-up for the valve and cylinder model parametrization and the real-time simulation platform to perform HILS experiments.

\section{HARDWARE SET-UP AND HARDWARE-IN- THE-LOOP SIMULATION PLATFORM}

A hydraulic apparatus that consists of a linear hydraulic actuator driven by a servo-solenoid valve, as shown in Fig. 1, was developed for identification of model's parameters and to perform HILS experiments. The system is equipped with a set of sensors to measure the system pressures and piston position. The valve ports and cylinder chambers pressures $P_{1}, P_{2}, P_{\mathrm{s}}$ and $P_{\mathrm{t}}$ are measured using four analogue pressure sensors. The cylinder rod position is acquired with a linear digital encoder with $1 \mu \mathrm{m}$ of resolution. The velocity was obtained by differentiation of the position signal. All the sensors and the valve electrical input are connected to a low-cost DSP-based real-time card (RTC) from dSPACE ${ }^{\circledR}[6]$, model DS1102, in such a way that real-time control and data acquisition can be performed.

To perform HILS experiments (see section 4), two DS1102 boards, installed in two different personal computers, were used as shown in Fig. 2. The control algorithms run in one of the RTCs, the other being responsible to run the real-time simulation of the cylinder and valve models. The real system is then connected to the controller, through a double switch, to acquire the data used in the HILS performance evaluation.

\section{PARAMETER IDENTIFICATION AND PARTIAL RESULTS}

This section presents the strategies and experiments performed for the identification of the parameters of the hybrid models proposed in Part 1 [7]. 

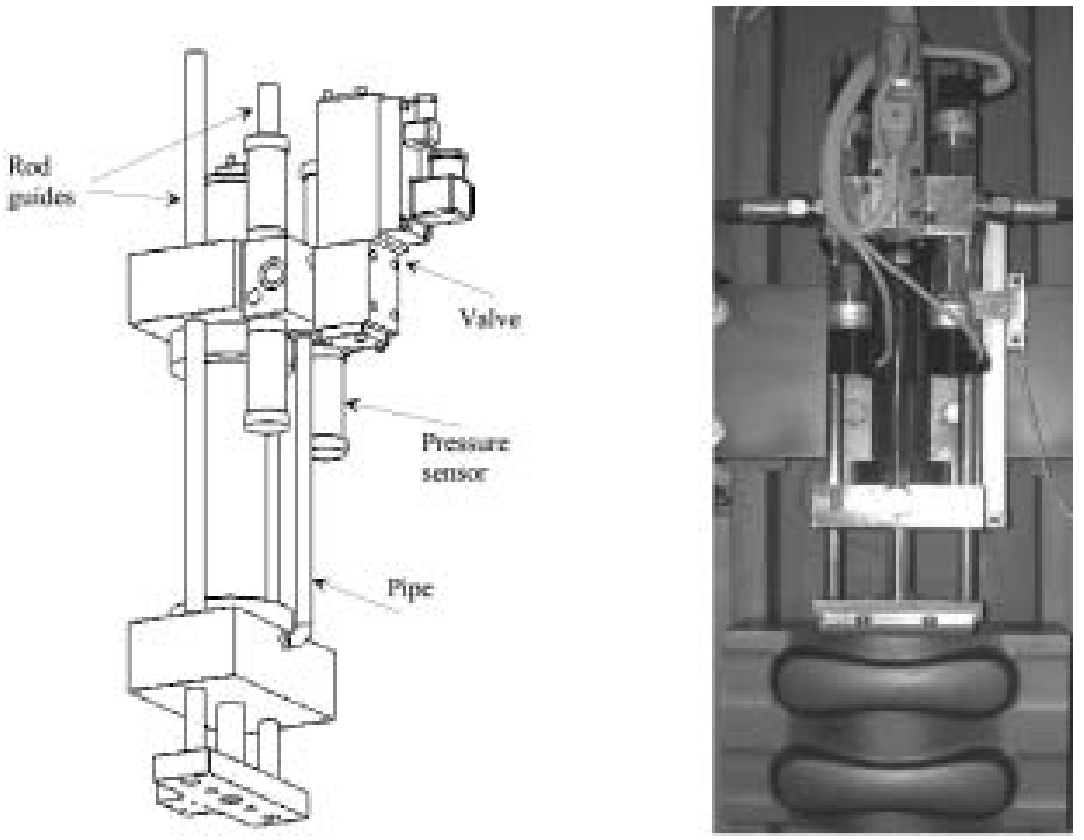

Fig. 1 Hydraulic test bed (draft and real system)

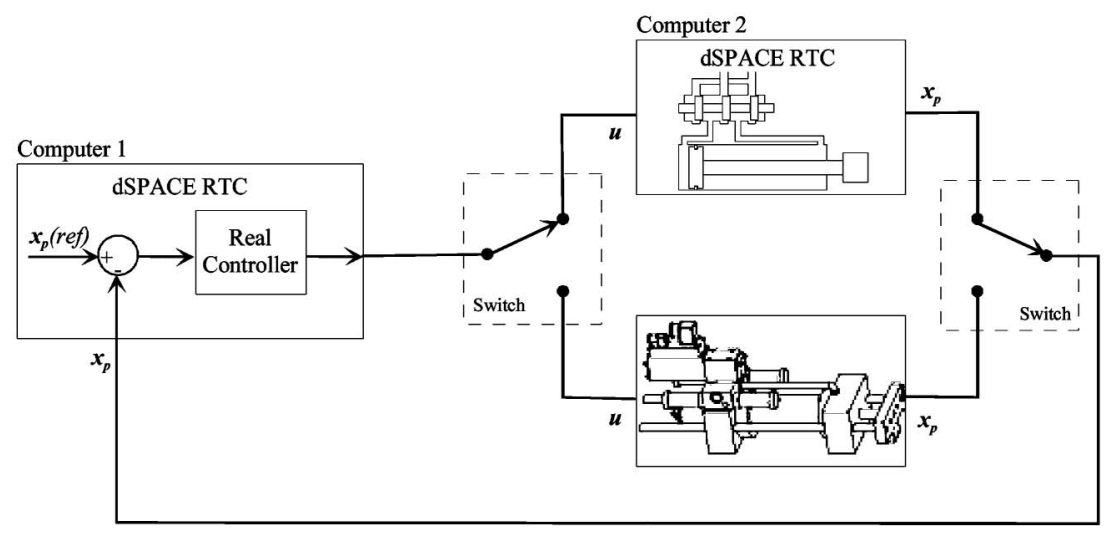

Fig. 2 HILS platform

\subsection{Valve model}

\subsubsection{Spool motion model parameters}

The spool motion model reproduces the frequency response amplitudes with a second-order model with acceleration and velocity saturation, with the phase lag adjusted with a delay. The least-squares method was used for the parameter estimation. The block diagram model, shown in Fig. 3, was simulated over a frequency range from 10 to $300 \mathrm{~Hz}$ in steps of $10 \mathrm{~Hz}$. The parameters were adjusted using three Bode amplitude curves available in the manufacturer data sheet $(5,25$ and 50 per cent of maximum amplitude). A variable frequency (and amplitude) sine wave $\bar{u}$ was applied to the input of

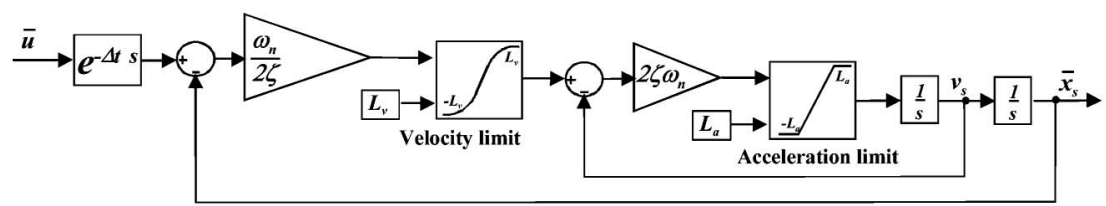

Fig. 3 Dynamic model for spool position with velocity and acceleration limits 
the dynamic model. The output spool position $\bar{x}_{\mathrm{s}}$ was then used to evaluate the output gain in decibels, $G s_{n}$. This gain was then compared with the data sheet gain at the same frequency and amplitude, $G r_{n}$. The cost function $F$ is calculated for each set of model parameters $\omega_{n}, \xi, L_{v}$ and $L_{a}$. The model parameters were selected for the minimum value of the function $F$. Because most of the valve action takes place near the middle position, a weighting factor of four was applied on the 5 per cent quadratic error when calculating the cost function value:

$$
\bar{u}=A_{\text {in }} \sin \left(2 \pi f_{n} t\right), \quad A_{\text {out }}=\left|\bar{x}_{\text {s }}\right|
$$

where $n=\{1,2, \ldots, 29,30\}, f_{n}=10 n$ and $t$ is the variable time.

The amplitude gain $G s=20 \log \left(A_{\text {out }} / A_{\text {in }}\right)$ is used to calculate the cost function:

$$
\begin{aligned}
F\left(\omega_{n}, \xi, L_{v}, L_{a}\right)= & \left.4 \sum_{n=1}^{30} \frac{\left(G s_{n}-G r_{n}\right)^{2}}{2}\right|_{A_{\text {in }}=5 \%} \\
& +\left.\sum_{n=1}^{30} \frac{\left(G s_{n}-G r_{n}\right)^{2}}{2}\right|_{A_{\text {in }}=25 \%} \\
& +\left.\sum_{n=1}^{30} \frac{\left(G s_{n}-G r_{n}\right)^{2}}{2}\right|_{A_{\text {in }}=50 \%}
\end{aligned}
$$

The following parameter set minimizes the cost function for the selected model: $\omega_{n}=1007.01 \mathrm{rad} / \mathrm{s}, \xi=0.48$, $L_{v}=125.56 \mathrm{~s}^{-1}$ and $L_{a}=81184.24 \mathrm{~s}^{-2}$.

The simulation results (dotted curves) presented in Fig. 4 show that the amplitude effects of non-modelled dynamic behaviour are more visible for frequencies higher then $200 \mathrm{~Hz}$. To adjust the phase curve for the different amplitudes a delay was used. The approach for the delay estimation was identical with that used for the amplitude response parameters. Analysing the results $\left(\Delta t=7.625 \times 10^{-4} \mathrm{~s}\right)$ presented in Fig. 4 , it can be con-

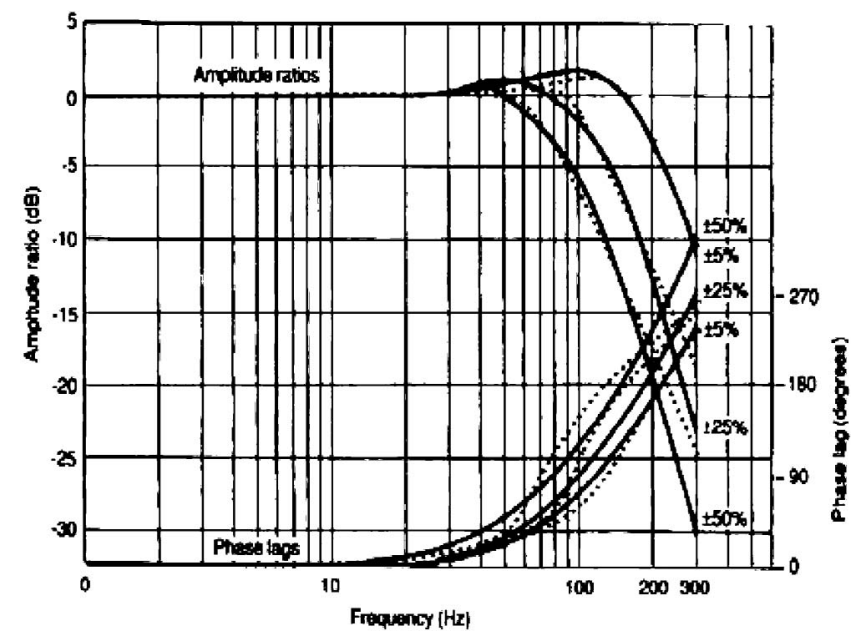

Fig. 4 Datasheet (-) and simulated $(\cdots)$ Bode diagrams for amplitude and phase lag response (by courtesy of Eaton Corporation) cluded that very good results are obtained for the 5 per cent input variation (for the valve application frequency range).

\subsubsection{Static parameters}

The static model equations proposed in Part 1 of the paper [7] for a symmetrical but unmatched valve uses four pseudo-section functions $A_{\mathrm{s} 1}\left(\bar{x}_{\mathrm{s}}\right), A_{\mathrm{s} 2}\left(\bar{x}_{\mathrm{s}}\right), A_{1 \mathrm{t}}\left(\bar{x}_{\mathrm{s}}\right)$ and $A_{2 \mathrm{t}}\left(\bar{x}_{\mathrm{s}}\right)$ and as follows:

$$
\begin{aligned}
& A_{\mathrm{s} 2}\left(\bar{x}_{\mathrm{s}}\right)=k_{1} \bar{x}_{\mathrm{s}}+k_{2}+\sqrt{k_{3} \bar{x}_{\mathrm{s}}^{2}+k_{4} \bar{x}_{\mathrm{s}}+k_{5}} \\
& A_{\mathrm{s} 1}\left(\bar{x}_{\mathrm{s}}\right)=-k_{1} \bar{x}_{\mathrm{s}}+k_{2}+\sqrt{k_{3} \bar{x}_{\mathrm{s}}^{2}-k_{4} \bar{x}_{\mathrm{s}}+k_{5}} \\
& A_{1 \mathrm{t}}\left(\bar{x}_{\mathrm{s}}\right)=k_{1 \mathrm{t}} \bar{x}_{\mathrm{s}}+k_{2 \mathrm{t}}+\sqrt{k_{3 \mathrm{t}} \bar{x}_{\mathrm{s}}^{2}+k_{4 \mathrm{t}} \bar{x}_{\mathrm{s}}+k_{5 \mathrm{t}}} \\
& A_{2 \mathrm{t}}\left(\bar{x}_{\mathrm{s}}\right)=-k_{1 \mathrm{t}} \bar{x}_{\mathrm{s}}+k_{2 \mathrm{t}}+\sqrt{k_{3 \mathrm{t}} \bar{x}_{\mathrm{s}}^{2}-k_{4 \mathrm{t}} \bar{x}_{\mathrm{s}}+k_{5 \mathrm{t}}}
\end{aligned}
$$

The $k_{i}$ parameters of $A_{\mathrm{s} 1}\left(\bar{x}_{\mathrm{s}}\right), A_{\mathrm{s} 2}\left(\bar{x}_{\mathrm{s}}\right), A_{1 \mathrm{t}}\left(\bar{x}_{\mathrm{s}}\right)$ and $A_{2 \mathrm{t}}\left(\bar{x}_{\mathrm{s}}\right)$ and can be estimated in order to reproduce the valve pressure gain and the valve flow gain. The valve used has the following static measured characteristics: $Q_{\mathrm{n}}=25.51 / \mathrm{min}, P_{\mathrm{n}}=35 \mathrm{bar}, P_{\mathrm{s}}=70 \mathrm{bar}, \bar{K}_{q o}=281 / \mathrm{min}$, $K_{p 0}=36.5, q_{1 \mathrm{k} 0}=1.36 \mathrm{l} / \mathrm{min}$, where $\bar{K}_{p 0}$ is the relative pressure gain at $\bar{x}_{\mathrm{s}}=0, \bar{K}_{q 0}$ is the flow gain at $\bar{x}_{\mathrm{s}}=0, P_{\mathrm{n}}$ is the nominal pressure drop, $q_{1 \mathrm{k} 0}$ is the leakage flow at $\bar{x}_{\mathrm{s}}=0, Q_{\mathrm{n}}$ is the nominal volumetric flowrate and $P_{\mathrm{s}}$ is the source pressure.

A characteristic of this type of valve is that the chamber pressures may not intercept at $P_{\mathrm{s}} / 2$, as can be seen later in Fig. 5a. The actual valve has the interception point at 43 bar for $P_{\mathrm{s}}=70$ bar, thus having a difference $\Delta P_{\mathrm{m}}=8$ bar relative to $P_{\mathrm{s}} / 2$. Using equations (2) and (4) (presented in Part 1) and considering that ports 1 and 2 are closed (pressure gain measurement), i.e. $Q_{1}=Q_{2}=0$, the following relation can be set for the pressure difference at the middle point:

$$
\Delta P_{\mathrm{m}}=\frac{P_{\mathrm{s}}}{2} \frac{A_{\mathrm{s} 2}(0)^{2}-A_{2 \mathrm{t}}(0)^{2}}{A_{\mathrm{s} 2}(0)^{2}+A_{2 \mathrm{t}}(0)^{2}}
$$

Using again equations (2) and (4) of Part 1 and $Q_{1}=Q_{2}=0$, the relative load pressure is given by

$$
\bar{P}_{\mathrm{L}}\left(x_{\mathrm{s}}\right)=\frac{A_{\mathrm{s} 1}\left(\bar{x}_{\mathrm{s}}\right)^{2}}{A_{\mathrm{s} 1}\left(\bar{x}_{\mathrm{s}}\right)^{2}+A_{1 \mathrm{t}}\left(\bar{x}_{\mathrm{s}}\right)^{2}}-\frac{A_{\mathrm{s} 2}\left(\bar{x}_{\mathrm{s}}\right)^{2}}{A_{\mathrm{s} 2}\left(\bar{x}_{\mathrm{s}}\right)^{2}+A_{2 \mathrm{t}}\left(\bar{x}_{\mathrm{s}}\right)^{2}}
$$

where $P_{\mathrm{L}}=P_{1}-P_{2}$ and $\bar{P}_{\mathrm{L}}=P_{\mathrm{L}} / P_{\mathrm{S}}$.

The pressure gain is then defined as

$$
\bar{K}_{p 0}=\left.\frac{\partial \bar{P}_{\mathrm{L}}\left(\bar{x}_{\mathrm{s}}\right)}{\partial \bar{x}_{\mathrm{s}}}\right|_{\bar{x}_{\mathrm{s}}=0}
$$




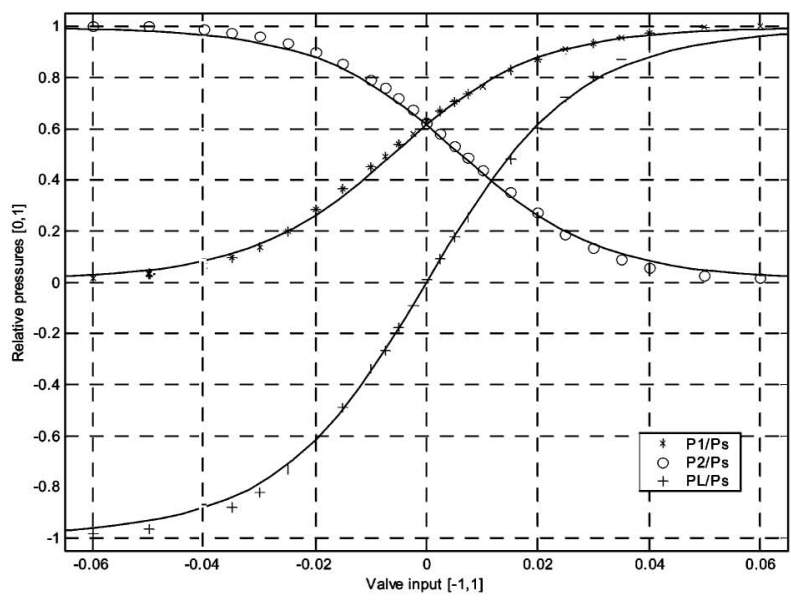

a) Relative pressures near middle position: $x_{s} \in|-6 \%, 6 \%|$.

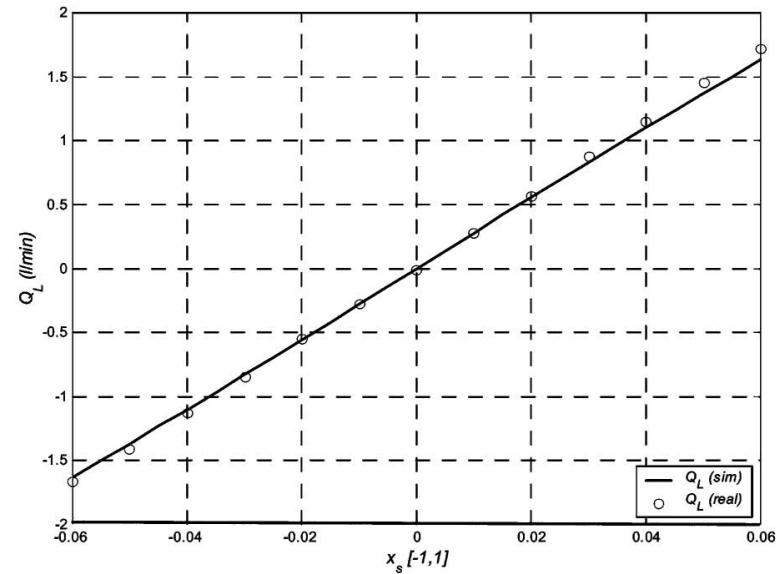

b) Load flow rate near middle position: $\bar{x}_{s} \in[-6 \%, 6 \%]$.

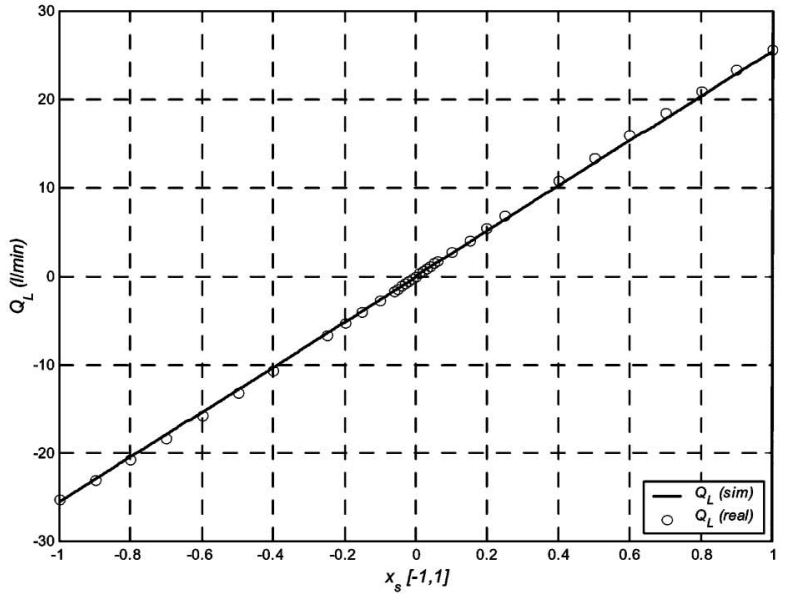

c) Load flow rate for $\bar{x}_{s} \in[-1,1]$.

Fig. 5 Real and simulated results of the static valve model

When measuring the flow gain that is connecting port 1 to port 2 (see Fig. 3 of Part 1 ) with a null resistance, the load flowrate $Q_{\mathrm{L}}$ can be expressed as $Q_{1}$ or by $Q_{2}$. Then using equations (2) and (4) of Part 1 and the chamber pressure difference to the middle point, $\Delta P_{\text {in }}$, the load flow is given by the following equation when $Q_{\mathrm{L}}=Q_{1}$ :

$$
Q_{\mathrm{L}}\left(\bar{x}_{\mathrm{s}}\right)=A_{\mathrm{s} 1}\left(\bar{x}_{\mathrm{s}}\right) \sqrt{\frac{P_{\mathrm{s}}}{2}-\Delta P_{\mathrm{m}}}-A_{1 \mathrm{t}}\left(\bar{x}_{\mathrm{s}}\right) \sqrt{\frac{P_{\mathrm{s}}}{2}+\Delta P_{\mathrm{m}}}
$$

The flow gain can be written as

$$
\begin{aligned}
\bar{K}_{q 0}= & \left.\frac{\partial Q_{\mathrm{L}}\left(\bar{x}_{\mathrm{s}}\right)}{\partial \bar{x}_{\mathrm{s}}}\right|_{\bar{x}_{\mathrm{s}}=0}=\left.\frac{\partial A_{\mathrm{s} 1}\left(\bar{x}_{\mathrm{s}}\right)}{\partial \bar{x}_{\mathrm{s}}}\right|_{\bar{x}_{\mathrm{s}}=0} \sqrt{\frac{P_{\mathrm{s}}}{2}-\Delta P_{\mathrm{m}}} \\
& -\left.\frac{\partial A_{1 \mathrm{t}}\left(\bar{x}_{\mathrm{s}}\right)}{\partial \bar{x}_{\mathrm{s}}}\right|_{\bar{x}_{\mathrm{s}}=0} \sqrt{\frac{P_{\mathrm{s}}}{2}+\Delta P_{\mathrm{m}}}
\end{aligned}
$$

Using $Q_{\mathrm{L}}=Q_{2}$, the flow gain can also be expressed by

$$
\begin{aligned}
\bar{K}_{q 0}= & \left.\frac{\partial A_{2 \mathrm{t}}\left(\bar{x}_{\mathrm{s}}\right)}{\partial \bar{x}_{\mathrm{s}}}\right|_{\bar{x}_{\mathrm{s}}=0} \sqrt{\frac{P_{\mathrm{s}}}{2}+\Delta P_{\mathrm{m}}} \\
& -\left.\frac{\partial A_{\mathrm{s} 2}\left(\bar{x}_{\mathrm{s}}\right)}{\partial \bar{x}_{\mathrm{s}}}\right|_{\bar{x}_{\mathrm{s}}=0} \sqrt{\frac{P_{\mathrm{s}}}{2}-\Delta P_{\mathrm{m}}}
\end{aligned}
$$

The flow outside the origin area can be adjusted with the nominal flow $Q_{\mathrm{n}}$ and nominal pressure $P_{\mathrm{n}}$, which can be measured for a specific valve or are available in the manufacturer's data sheet, as $A_{\mathrm{s} 2}\left(\bar{x}_{\mathrm{s}}\right) \approx A_{1 \mathrm{t}}\left(\bar{x}_{\mathrm{s}}\right) \approx 0$ for $\bar{x}_{\mathrm{s}}=1$ :

$$
\begin{aligned}
& \frac{Q_{\mathrm{n}}}{\sqrt{P_{\mathrm{n}}}}=\left.A_{\mathrm{s} 1}\left(\bar{x}_{\mathrm{s}}\right)\right|_{\overline{\mathrm{s}}_{\mathrm{s}}=1} \\
& \frac{Q_{\mathrm{n}}}{\sqrt{P_{\mathrm{n}}}}=\left.A_{2 \mathrm{t}}\left(\bar{x}_{\mathrm{s}}\right)\right|_{\bar{x}_{\mathrm{s}}=1}
\end{aligned}
$$

Proc. Instn Mech. Engrs Vol. 218 Part I: J. Systems and Control Engineering 
The leakage flow can be expressed as a function of the relative valve chamber pressures, $\bar{P}_{1}=P_{1} / P_{\mathrm{s}}$ and $\bar{P}_{2}=P_{2} / P_{\text {s }}$, using equations (2) and (3) of Part 1 when $Q_{1}=Q_{2}=0$ :

$$
\begin{aligned}
q_{1 \mathrm{k}}\left(\bar{x}_{\mathrm{s}}\right) & =q_{\mathrm{s} 1}+q_{\mathrm{s} 2} \\
& =A_{\mathrm{s} 1}\left(\bar{x}_{\mathrm{s}}\right) \sqrt{P_{\mathrm{s}}\left(1-\bar{P}_{1}\right)}+A_{\mathrm{s} 2}\left(\bar{x}_{\mathrm{s}}\right) \sqrt{P_{\mathrm{s}}\left(1-\bar{P}_{\mathrm{s}}\right)} \\
q_{1 \mathrm{k}}\left(\bar{x}_{\mathrm{s}}\right) & =q_{1 \mathrm{t}}+q_{2 \mathrm{t}} \\
& =A_{1 \mathrm{t}}\left(\bar{x}_{\mathrm{s}}\right) \sqrt{P_{\mathrm{s}} \bar{P}_{1}}+A_{2 \mathrm{t}}\left(\bar{x}_{\mathrm{s}}\right) \sqrt{P_{\mathrm{s}} \bar{P}_{2}}
\end{aligned}
$$

Assuming the conditions $\bar{P}_{1} \approx 1$ and $\bar{P}_{2} \approx 0$, and using equations (12) and (13), new relations can be stated for the leakage flow and leakage flow derivative at a certain spool position. If the leakage flow curve is available, a measurement at a certain position $\left(\bar{x}_{\mathrm{s}}>0\right)$ can be used; otherwise the leakage at $\bar{x}_{\mathrm{s}}=1$ can be set to a very small value or even zero:

$$
\begin{aligned}
& \left.q_{1 \mathrm{k}}\right|_{\bar{P}_{1}=1} ^{\bar{P}_{2}=0}=\sqrt{P_{\mathrm{s}}} A_{\mathrm{s} 2}\left(\bar{x}_{\mathrm{s}}\right) \\
& \left.q_{\mathrm{lk}}\right|_{\bar{P}_{1}=1}=\sqrt{P_{\mathrm{s}}} A_{1 \mathrm{t}}\left(\bar{x}_{\mathrm{s}}\right) \\
& \left.\frac{\partial q_{1 \mathrm{k}}}{\partial x_{\mathrm{s}}}\right|_{\substack{\bar{P}_{1}=1 \\
\bar{P}_{2}=0}}=\left.\sqrt{P_{\mathrm{s}}} \frac{\partial A_{\mathrm{s} 2}\left(\bar{x}_{\mathrm{s}}\right)}{\partial \bar{x}_{\mathrm{s}}}\right|_{\substack{\bar{P}_{1}=1 \\
\bar{P}_{2}=0}} \\
& \left.\frac{\partial q_{1 \mathrm{k}}}{\partial x_{\mathrm{s}}}\right|_{\bar{P}_{\bar{P}_{2}=1}=0}=\left.\sqrt{P_{\mathrm{s}}} \frac{\partial A_{1 \mathrm{t}}\left(\bar{x}_{\mathrm{s}}\right)}{\partial \bar{x}_{\mathrm{s}}}\right|_{\bar{P}_{\bar{P}_{1}=1}=0}
\end{aligned}
$$

Using equation ( 3 ) for the pseudo-section functions, ten equations can be stated to solve for the $k_{i}$ and $k_{i \text { t }}$ pseudosection parameters model. Thus, using equations (4), (5), (8), (9), (10), (11), (14), (15), (16) and (17), and considering that the leakage flows and their derivatives are zero for $\bar{x}_{\mathrm{s}}=1$ (where $\bar{P}_{1}=1$ and $\bar{P}_{2}=0$ ), the pseudosection equation parameters $k_{i}$, [see equation (3)], are as following:

$$
\begin{aligned}
& k_{1}=-2.136, \quad k_{2}=1.602 \times 10^{-2}, \quad k_{3}=4.561 \\
& k_{4}=-8.084 \times 10^{-2}, \quad k_{5}=1.563 \times 10^{-2} \\
& k_{1 \mathrm{t}}=-2.145, \quad k_{2 \mathrm{t}}=7.276 \times 10^{-3}, \quad k_{3 \mathrm{t}}=4.602 \\
& k_{4 \mathrm{t}}=-4.208 \times 10^{-2}, \quad k_{5 \mathrm{t}}=1.092 \times 10^{-2}
\end{aligned}
$$

The results for the relative pressures and load flowrates obtained from the simulation of the static valve model are presented in Fig. 5.

\subsection{Cylinder model}

\subsubsection{The effective bulk modulus}

The effective bulk modulus $\beta_{\mathrm{e}}$, was estimated through the comparison of the maximum cylinder piston acceleration and its occurring frequency (natural frequency of the system) with the results of the simulation of a linear version of the whole system. The experimental block diagram used to measure the natural frequency is shown in Fig. 6. The system has to run in closed loop around $X_{\mathrm{p} 0}$ because of the different cylinder areas and because of the difficulties in setting the valve middle position. The system is linearized around $\left[\begin{array}{lllll}P_{10} & P_{20} & X_{\mathrm{p} 0} & V_{\mathrm{p} 0} & \bar{X}_{\mathrm{s} 0}\end{array}\right]^{\mathrm{T}}$. These values are obtained from the steady state conditions of velocity and acceleration equal to zero, which occur for $\bar{X}_{\text {s } 0}=0.009$ where $P_{1}=P_{10}$ and $P_{2}=P_{20}$. In this situation the resulting force is zero, i.e. $A_{1} P_{10}+M g-A_{2} P_{20}=0$ and, with $P_{\mathrm{s}}=P_{10}+P_{20}$ [9], the equilibrium pressures are given by

$$
P_{10}=\frac{A_{2} P_{\mathrm{s}}-M g}{A_{1}+A_{2}}, \quad P_{20}=\frac{A_{1} P_{\mathrm{s}}+M g}{A_{1}+A_{2}}
$$

where $g$ is the acceleration due to gravity.

At the position $X_{\mathrm{p} 0}=82 \mathrm{~mm}$ the chamber volumes are almost the same. The cylinder areas are $A_{1}=1.2566 \times$ $10^{-3} \mathrm{~m}^{2}$ and $A_{2}=8.7650 \times 10^{-4} \mathrm{~m}^{2}$.

The valve static characteristics at the linearized points have the measured values

$$
\begin{aligned}
& k_{q 1}=\left.\frac{\partial Q_{1}}{\partial \bar{x}_{\mathrm{s}}}\right|_{\bar{X}_{\mathrm{s} 0}}=4.76 \times 10^{-4} \sqrt{\frac{P_{\mathrm{s}}}{2 P_{\mathrm{n}}}} \mathrm{m}^{3} / \mathrm{s} ; \\
& k_{q 2}=\left.\frac{\partial Q_{2}}{\partial \bar{x}_{\mathrm{s}}}\right|_{\bar{X}_{\mathrm{s} 0}}=4.76 \times 10^{-4} \sqrt{\frac{P_{\mathrm{s}}}{2 P_{\mathrm{n}}}} \mathrm{m}^{3} / \mathrm{s} \\
& k_{p 1}=\left.\frac{\partial P_{1}}{\partial \bar{x}_{\mathrm{s}}}\right|_{\bar{X}_{\mathrm{s} 0}}=19 P_{\mathrm{s}} \mathrm{Pa}, \quad k_{p 2}=\left.\frac{\partial P_{2}}{\partial \bar{x}_{\mathrm{s}}}\right|_{\bar{X}_{\mathrm{s} 0}}=-15.6 P_{\mathrm{s}} \mathrm{Pa}
\end{aligned}
$$

where $k_{q 1}$ is the flow gain at $\bar{X}_{\mathrm{s} 0}, k_{q 2}$ is the flow gain at $\bar{X}_{\mathrm{s} 0}, k_{p 1}$ is the pressure gain (in chamber 1 at $\bar{X}_{\mathrm{s} 0}$, and $k_{p 2}$ is the pressure gain in chamber 2 at $\bar{X}_{\mathrm{s} 0}$. The flow-pressure coefficients are then defined as

$$
k_{\mathrm{c} 2}=-\frac{k_{q 2}}{k_{p 2}}, \quad k_{\mathrm{c} 1}=\frac{k_{q 1}}{k_{p 1}}
$$

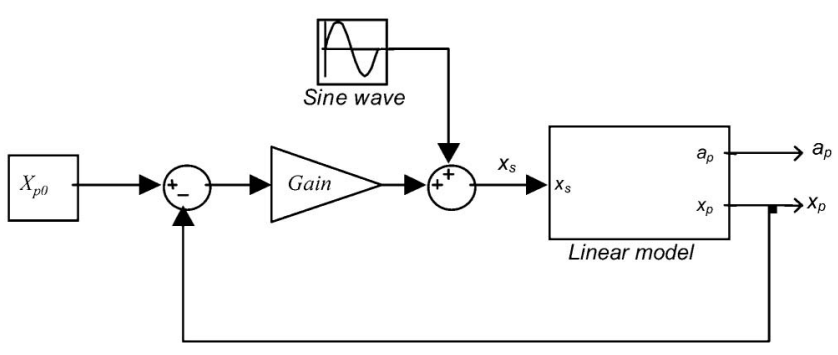

Fig. 6 Block diagram to measure the natural frequency

I03504 (C) IMechE 2004 
The linearized cylinder and valve equations are expressed in state space format and were simulated in the Simulink ${ }^{\circledR}$ [10] environment:

$$
\begin{aligned}
& {\left[\begin{array}{c}
\delta \dot{p}_{1} \\
\delta \dot{p}_{2} \\
\delta \dot{v}_{\mathrm{p}} \\
\delta \dot{x}_{\mathrm{p}}
\end{array}\right]=\left[\begin{array}{cccc}
-\frac{\beta_{\mathrm{e} 1}}{V_{1}} K_{\mathrm{c} 1} & 0 & -\frac{\beta_{\mathrm{e} 1}}{V_{1}} A_{1} & 0 \\
0 & -\frac{\beta_{\mathrm{e} 2}}{V_{2}} K_{\mathrm{c} 2} & \frac{\beta_{\mathrm{e} 2}}{V_{2}} A_{2} & 0 \\
\frac{A_{1}}{M} & -\frac{A_{2}}{M} & -\frac{f}{M} & 0 \\
0 & 0 & 1 & 0
\end{array}\right]} \\
& \times\left[\begin{array}{c}
\delta p_{1} \\
\delta p_{2} \\
\delta v_{\mathrm{p}} \\
\delta x_{\mathrm{p}}
\end{array}\right]+\left[\begin{array}{cc}
\frac{\beta_{\mathrm{e} 1}}{V_{1}} K_{q 1} & 0 \\
-\frac{\beta_{\mathrm{e} 2}}{V_{2}} K_{q 2} & 0 \\
0 & 1 \\
0 & 0
\end{array}\right]\left[\begin{array}{c}
\delta \bar{x}_{\mathrm{s}} \\
g
\end{array}\right] \\
& {\left[\begin{array}{c}
\delta v_{\mathrm{p}} \\
\delta x_{\mathrm{p}}
\end{array}\right]=\left[\begin{array}{llll}
0 & 0 & 1 & 0 \\
0 & 0 & 0 & 1
\end{array}\right]\left[\begin{array}{c}
\delta p_{1} \\
\delta p_{2} \\
\delta v_{\mathrm{p}} \\
\delta x_{\mathrm{p}}
\end{array}\right]}
\end{aligned}
$$

where $V_{1}=V_{01}+A_{1} X_{\mathrm{p} 0}$ and $V_{2}=V_{02}+A_{2}\left(L-X_{\mathrm{p} 0}\right)$ are the equilibrium volumes and where $V_{01}=3 \times 10^{-5} \mathrm{~m}^{3}$ and $V_{02}=5 \times 10^{-5} \mathrm{~m}^{3}$ are used for dead volumes of the lines and valve chambers respectively. $M$ represents all the mass in motion and equals $80 \mathrm{~kg}$. The linearized version of the friction model (Part 1) [7] is only valid for small displacements (less than $15 \mu \mathrm{m}$ ) where the seal deformation (variable $z$ ) is equal to the piston displacement $x_{\mathrm{p}} ;$ i.e. it is assumed that the piston is in the stiction state. The friction factor $f$ is then intended to model all the friction effects (valve and cylinder) that occur when the spool velocity sign have fast changes.

The effective bulk modulus $\beta_{\mathrm{e}}$ and friction factor $f$ were estimated by an optimization process that minimizes the distance (in the acceleration-frequency plane) between the real and simulated piston maximum acceleration. The amplitudes of the acceleration signals measured with $\beta_{\mathrm{e} 1}=7.7 \times 10^{8} \mathrm{~Pa}, \beta_{\mathrm{e} 2}=9.6 \times 10^{8} \mathrm{~Pa}$ and $f=8100 \mathrm{~N} \mathrm{~s} / \mathrm{m}$ are presented in Fig. 7. The piston acceleration was measured with a high bandwidth accelerometer from 1 to $130 \mathrm{~Hz}$. The experience shown in Fig. 6 was repeated for several source pressures in order to evaluate the effective bulk modulus as a function of the pressure. Figure 8 shows the evolution of the real $\beta_{\mathrm{e}}$ with the chamber pressure and $\beta_{\mathrm{e}}$ calculated with equation (21). The parameters for the equation (21) were obtained by optimization and

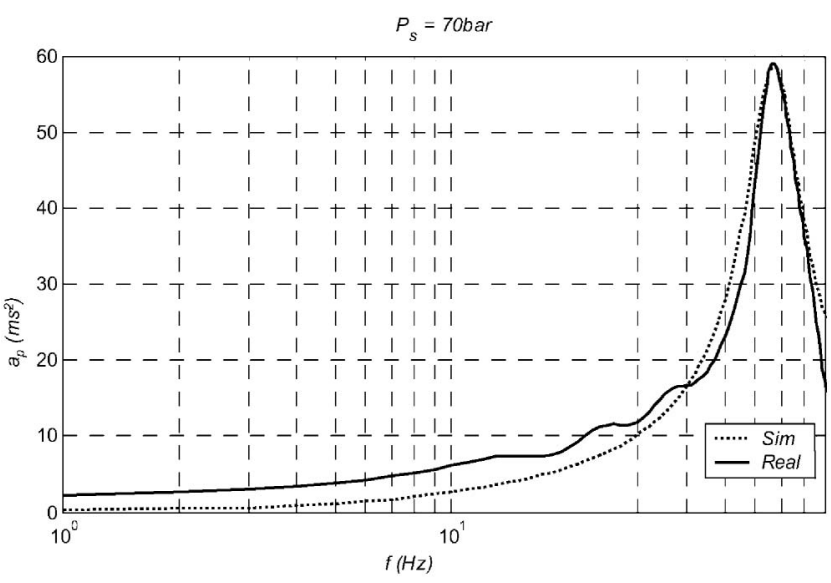

Fig. 7 Acceleration versus frequency plot

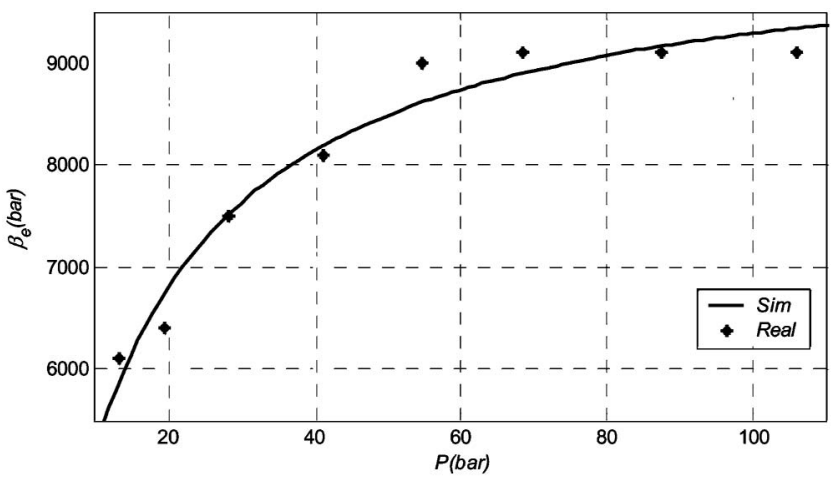

Fig. 8 Effective bulk modulus versus chamber pressure

have the values $B=9.71 \times 10^{-10}$ and $C=1.15 \times 10^{-3}$ :

$$
\beta_{\mathrm{e}}=\frac{10^{5}+P}{B P+C}
$$

where $B\left(\mathrm{~Pa}^{-1}\right)$ and $C$ are constants related to the oil characteristics of the model proposed in reference [11].

\subsubsection{The cylinder leakage conductance}

The internal cylinder leakage is assumed laminar and is represented by a conductance defined as

$$
g_{1 \mathrm{kc}}=\frac{q_{\mathrm{lkc}}}{P_{1}-P_{2}}
$$

The leakage flowrate is measured indirectly in the following way. In the initial piston position $x_{\mathrm{p}}=0$, port 2 of the valve was trapped, port 1 is open to atmosphere and the cylinder was allowed to run in a free way with a heavy load. The piston position and chamber pressure were measured over a long period $\Delta t$ of time in order to obtain a constant velocity in steady state, $v_{\mathrm{ps}}$. The leakage conductance can then be calculated from

$$
g_{1 \mathrm{kc}}=\frac{v_{\mathrm{ps}} A_{2}}{P_{2}}
$$

Proc. Instn Mech. Engrs Vol. 218 Part I: J. Systems and Control Engineering 
The piston position and the pressure in chamber 2 were measured for a period of time $\Delta t=200 \mathrm{~s}$. The total displacement, in this period, was $1504 \mu \mathrm{m}$, and the pressure mean value was $P_{2}=5.28$ bar. The value obtained for the internal leakage conductance was $g_{1 \mathrm{kc}}=1.248 \times 10^{-14} \mathrm{~m}^{3} / \mathrm{s} \mathrm{Pa}$.

\subsubsection{Friction model}

Estimation of the static parameters $F_{\mathrm{CO}}, F_{\mathrm{S}}, v_{\mathrm{S}}$ and $K_{\mathrm{v}}$ and the dynamic parameters $\sigma_{0}$ and $\sigma_{1}$ for the LuGre friction model (see section 3 in Part 1 [7]) are presented below.

(a) Identification of the static parameters. The static parameters are estimated from the velocity-frictional force curve measured with constant velocities. The sample time was $5 \mathrm{~ms}$, with the frictional forces and velocities being calculated with 20 samples in order to minimize the noise effects. The experiments at constant velocities were performed with closed-loop velocity control.

At constant velocity (a steady state situation, $a_{\mathrm{p}}=0$ ), with the platform in the horizontal position, the friction force can be measured through the chamber pressures [see equation (5) in Part 1]:

$$
F_{\mathrm{f}}=P_{1} A_{1}-P_{2} A_{2}
$$

The frictional force was measured for constant velocities between -0.2 and $0.2 \mathrm{~m} / \mathrm{s}$.

At constant velocity the state variable $z$ of the friction model [equations (10) to (12) of Part 1] is constant, $\mathrm{d} z / \mathrm{d} t=0$, and the friction force can be estimated from

$$
\hat{F}_{\mathrm{f}}=\left[\hat{F}_{\mathrm{CO}}+\left(\hat{F}_{\mathrm{S}}-\hat{F}_{\mathrm{CO}}\right) \mathrm{e}^{-\left(v_{\mathrm{p}} / \hat{v}_{\mathrm{S}}\right)^{2}}\right] \operatorname{sgn}\left(v_{\mathrm{p}}\right)+\hat{K}_{\mathrm{v}} v_{\mathrm{p}}
$$

where $\hat{F}_{\mathrm{CO}}, \hat{F}_{\mathrm{S}}, \hat{v}_{\mathrm{S}}$ and $\hat{K}_{\mathrm{v}}$ are the estimated static parameters and $\hat{F}_{\mathrm{f}}$ is the estimated frictional force.

For the parameter estimation the least-squares method was used for the cost function cf:

$$
\mathrm{cf}=\sum_{i=1}^{n}\left[F_{\mathrm{f}}\left(v_{i}\right)-\hat{F}_{\mathrm{f}}\left(v_{i}\right)\right]^{2}
$$

where $v_{i}$ are the measured velocities.

The cost function was calculated for each parameter set $\left(\hat{F}_{\mathrm{CO}}, \hat{F}_{\mathrm{S}}, \hat{v}_{\mathrm{S}}, \hat{K}_{\mathrm{v}}\right)$ given by the Simplex algorithm used in the fminsearch function of the MATLAB ${ }^{\circledR}$ [12] optimization toolbox [13]. Initial values for the parameters were obtained from the measured velocity versus frictional force curve. The static parameters to be used are those that minimize the cost function.

For a symmetrical friction model, i.e. the same model parameters for positive and negative velocities, the estimated parameters are

$$
\begin{aligned}
& \hat{F}_{\mathrm{CO}}=101.8 N, \quad \hat{F}_{\mathrm{S}}-\hat{F}_{\mathrm{CO}}=153.0 N \\
& \hat{v}_{\mathrm{S}}=0.019 \mathrm{~m} / \mathrm{s}, \quad \hat{K}_{\mathrm{v}}=1090 \mathrm{~N} \mathrm{~s} / \mathrm{m}
\end{aligned}
$$

As the measured frictional forces denote different parameters for different signs of velocity, the model can be enhanced with different parameters for negative and positive velocities. The new estimated parameters are then

$$
\begin{aligned}
& \hat{F}_{\mathrm{COn}}=89.26 \mathrm{~N}, \quad\left(\hat{F}_{\mathrm{Sn}}-\hat{F}_{\mathrm{COn}}\right)=160.3 \mathrm{~N} \\
& \hat{v}_{\mathrm{Sn}}=0.0251 \mathrm{~m} / \mathrm{s}, \quad \hat{K}_{\mathrm{vn}}=1387 \mathrm{~N} \mathrm{~s} / \mathrm{m} \\
& \hat{F}_{\mathrm{COp}}=110.2 \mathrm{~N}, \quad\left(\hat{F}_{\mathrm{Sp}}-\hat{F}_{\mathrm{COp}}\right)=150.8 \mathrm{~N} \\
& \hat{v}_{\mathrm{Sp}}=0.0152 \mathrm{~m} / \mathrm{s}, \quad \hat{K}_{\mathrm{vp}}=818.4 \mathrm{~N} \mathrm{~s} / \mathrm{m}
\end{aligned}
$$

where the subscripts $\mathrm{n}$ and $\mathrm{p}$ indicate negative and positive velocities respectively.

The comparison of the measured static frictional forces and those obtained from the symmetric and nonsymmetric static friction models is presented in Fig. 9.

(b) Identification of the dynamic parameters. The strategy for the identification of the dynamic parameters $\sigma_{0}$ and $\sigma_{1}$ consists in matching the real hydraulic force with the equivalent hydraulic force, obtained for the same conditions, from the simulation of the non-linear valve plus cylinder model. The non-symmetric static friction parameters were used. The identification used openloop experiments, with the valve and cylinder models enhancing the visibility of the dynamic parameters. The system working in the horizontal direction was excited with a sinusoidal signal with sufficient amplitude to lead the system in and out of the stiction state; i.e. the resulting force should be, during simulation, larger and lower than the breakaway force.

An optimization method, such as that used for estimation of the static parameters, was used to identify the dynamic parameters. The cost function is

$$
\operatorname{cf}\left(F_{\mathrm{h}}, F_{\mathrm{hm}}, \hat{\sigma}\right)=\sum_{k=1}^{n}\left[F_{\mathrm{h}}(k)-F_{\mathrm{hm}}(k, \hat{\sigma})\right]^{2}
$$

where $F_{\mathrm{h}}(k)$ is the $k$ sample of the real hydraulic force (sample time equal to $10 \mathrm{~ms}$ ) and $F_{\mathrm{hm}}(k, \hat{\sigma})$ is the hydraulic force that results from the model simulation with the same initial conditions, for the same time instant.

The utilization of the hydraulic force as the comparison force results from the following simplification. The net acceleration force is given by

$$
M \frac{\mathrm{d} v_{\mathrm{p}}}{\mathrm{d} t}=F_{\mathrm{h}}-F_{\mathrm{f}}
$$

With the mass used in the tests (piston plus rod), as the maximum values of $M \mathrm{~d} v_{\mathrm{p}} / \mathrm{d} t$ are less then $0.05 \mathrm{~N}$, this force is negligible when compared with the hydraulic and frictional forces.

The comparison of the hydraulic forces, the cylinder chamber pressures, the spool position and the piston velocity, when simulating the model with the nonsymmetrical friction static parameters, is presented in Fig. 10. The estimated dynamic parameters are $\sigma_{0}=$ $2.114 \times 10^{7} \mathrm{~N} / \mathrm{m}$ and $\sigma_{1}=2.914 \times 10^{3} \mathrm{~N} \mathrm{~s} / \mathrm{m}$. 

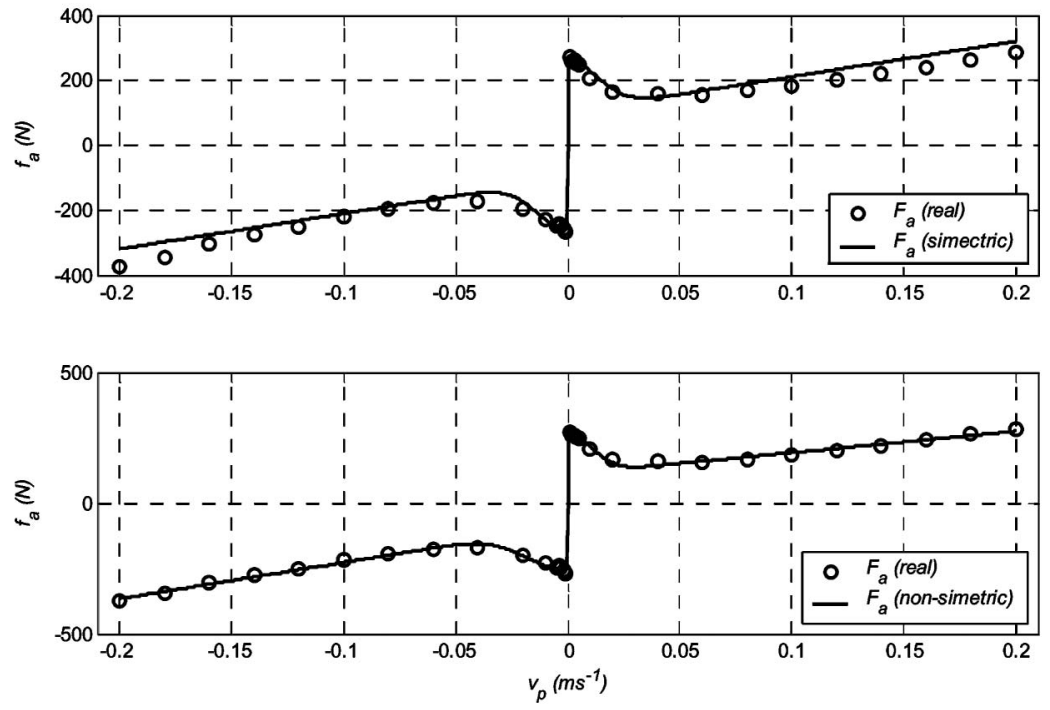

Fig. 9 Frictional force versus velocity steady state curves
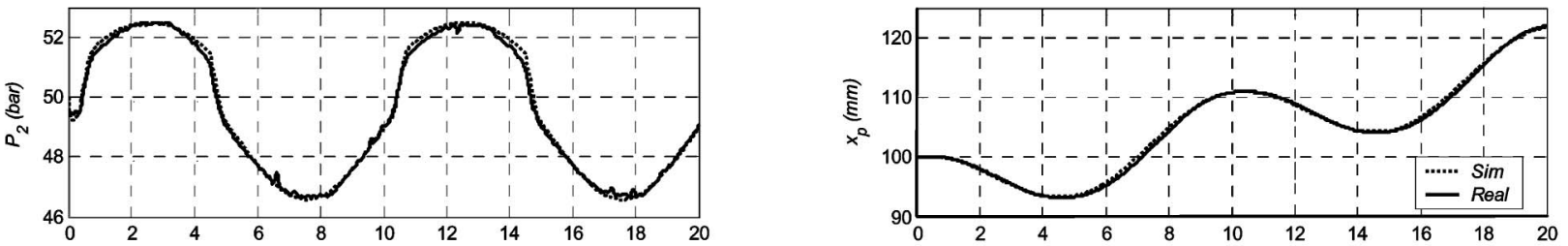

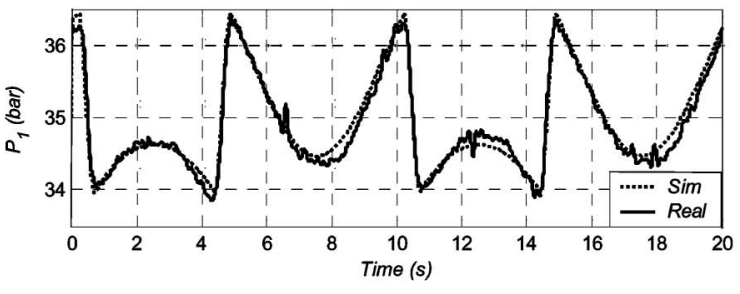

a) System and model chamber pressures.

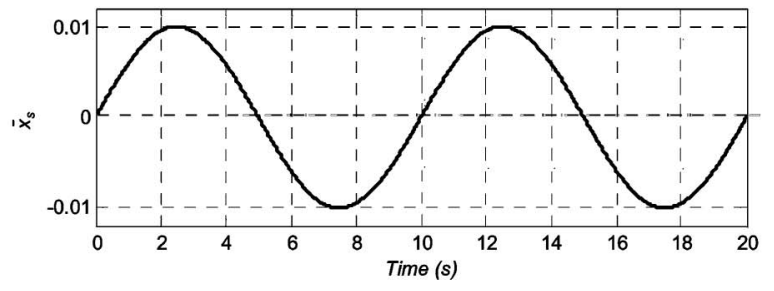

b) Piston position and valve spool position.

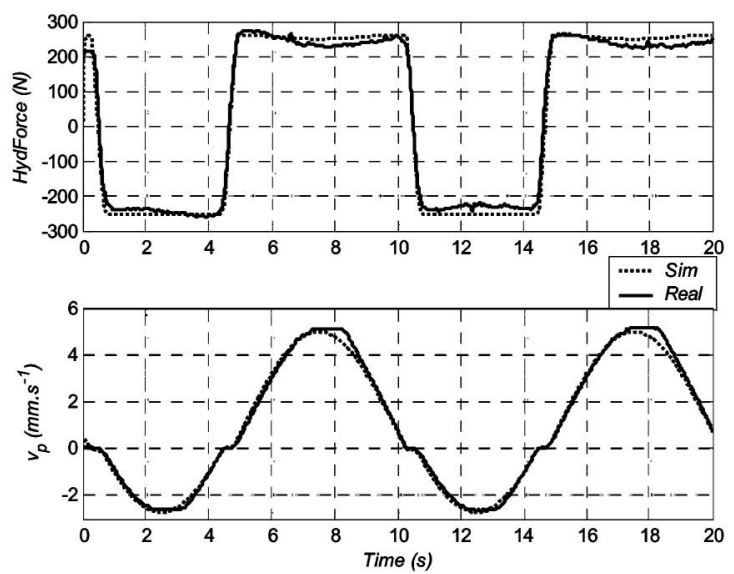

c) Hydraulic force and piston velocity.

Fig. 10 Comparison between the real and simulated systems when using the non-symmetrical friction static model 


\section{HARDWARE-IN-THE-LOOP SIMULATION EXPERIMENTS}

A Simulink ${ }^{\circledR}$ block implementing the cylinder hybrid state chart [7] and the valve model was used. The model was simulated in real time with a third-order explicit solver and a fixed step size of $0.5 \mathrm{~ms}$.

Closed-loop position control experiments, with pointto-point position trajectory as the input reference signal, were performed. Figure 11 shows the comparisons between the two experiments when controlled by proportional control, with the proportional constant equal to 50 and a moved mass of $80 \mathrm{~kg}$.

The experiment presented in Fig. 12 intends to evaluate the performance of the real and simulated systems when the desired input trajectories are steps and ramps. In this experiment a pressure source with $P_{\mathrm{s}}=120$ bar was used with a proportional gain $K_{\mathrm{p}}=100$.

From the results of the above experiments it can be said that the system model presents a satisfactory performance at small velocities and at trajectories with high-frequency content. A similar set of simulations was produced using a commercial library of hydraulic components [14]. The cylinder end stops are modelled with
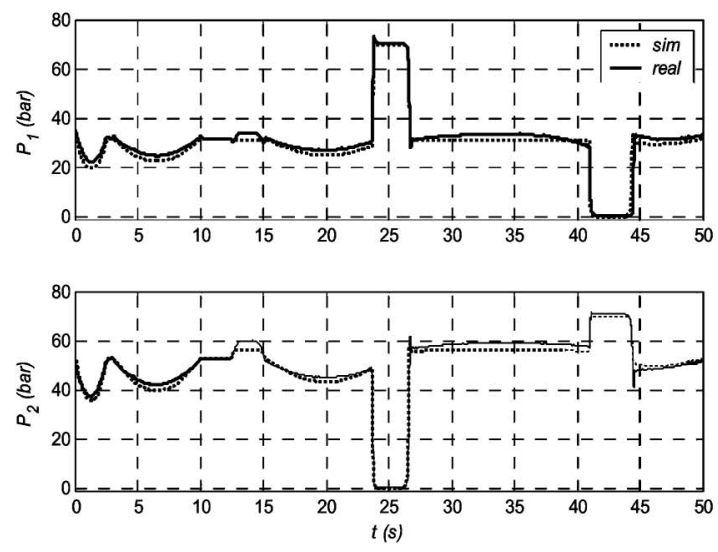

a) Cylinder chamber pressures.
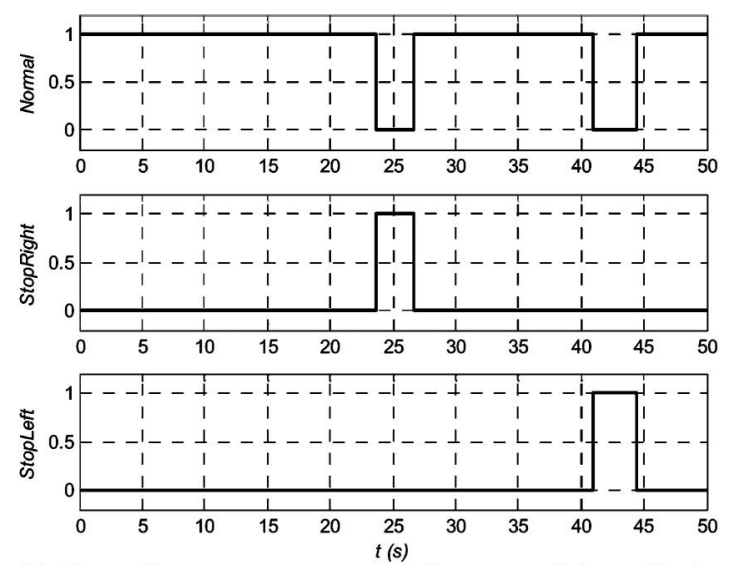

b) Time diagram representing the state of the cylinder. the usual spring and damper components (spring stiffness equal to $10^{10} \mathrm{~N} / \mathrm{m}$ and the damper coefficient equal to $10^{10} \mathrm{~N} / \mathrm{m} \mathrm{s}$ ) and the seal friction model only considers the viscous friction component. The overall system needs a third-order fixed-step solver with a $2 \mu$ s step size in order to run properly, negating real-time operation with low-cost hardware.

\section{CONCLUSIONS}

A model of a hydraulic system composed of a highperformance proportional valve and a hydraulic cylinder presented in Part 1 [7], was fully parametrized. Most of the used models are semiempirical with their parameters being calculated with simple methods or by optimization. The static valve parameters are calculated by solving a non-linear equation system. This equation system is specified in order to reproduce the relevant static characteristics available from the manufacturer's data or from experimental measurements. The parameters of the dynamic part of the valve and of the friction model are determined with optimization techniques.

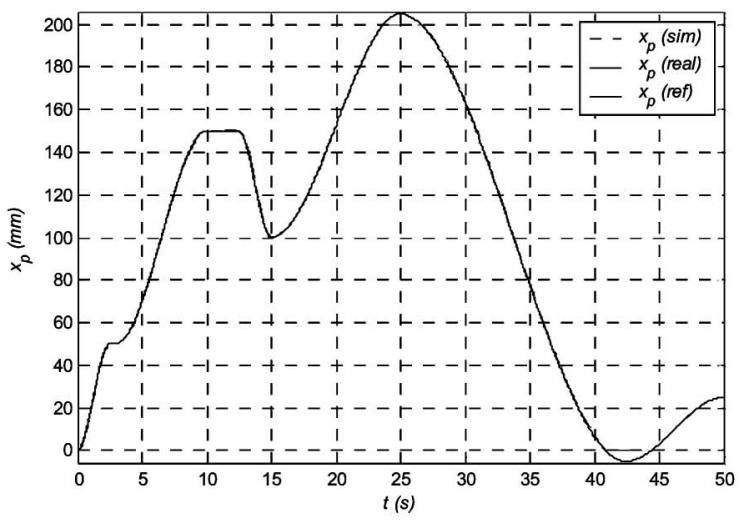

c) Reference, real and simulated piston position.

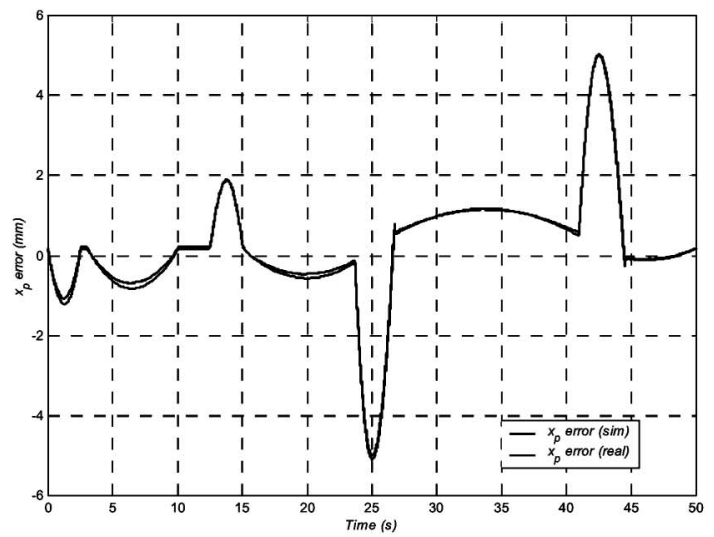

d) Real and simulated position error.

Fig. 11 HILS experimental and simulated results 


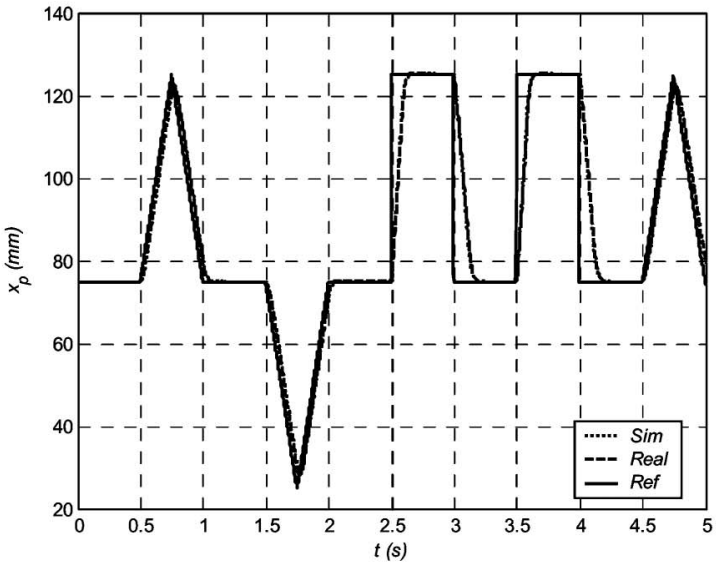

a) Piston position (reference, real and simulated).

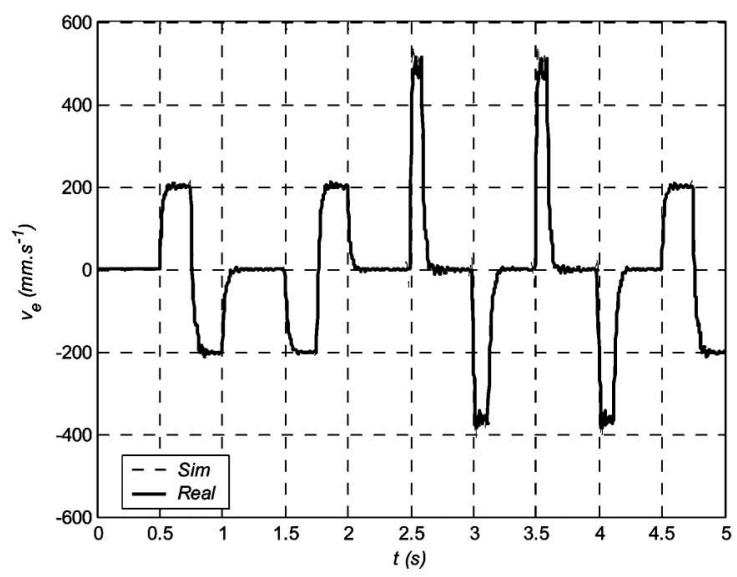

b) Piston velocity (real and simulated).

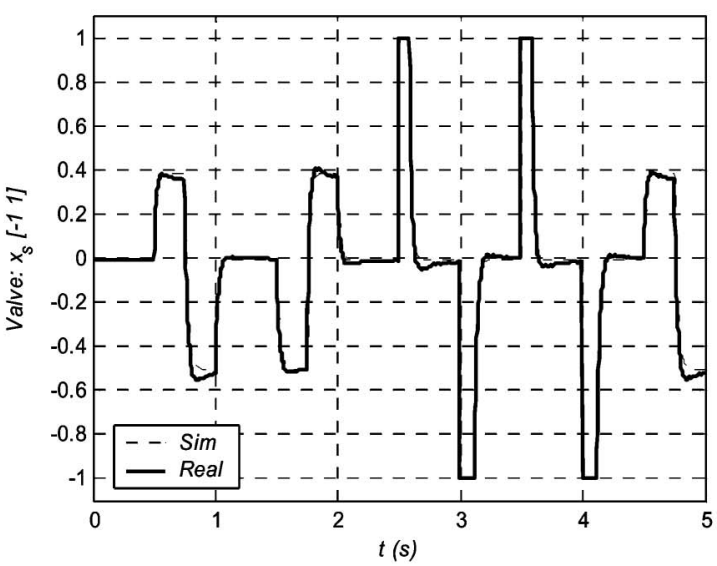

c) Valve input signal (real and simulated).

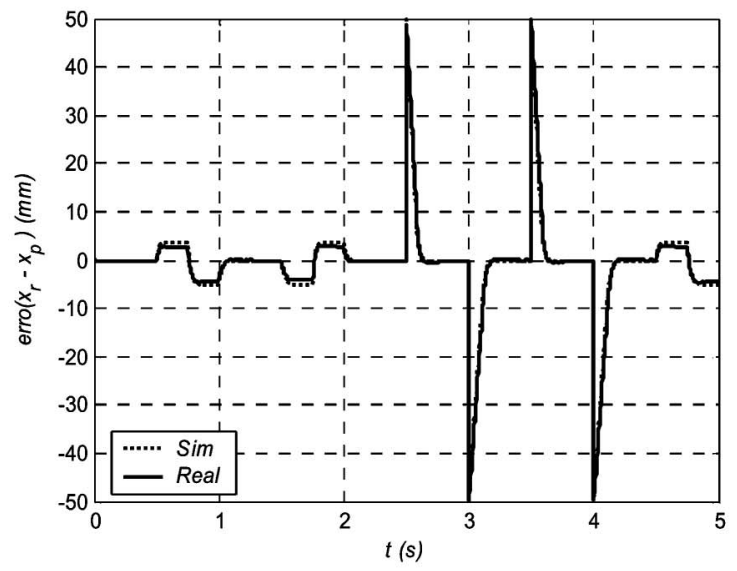

d) Real and simulated position error.

Fig. 12 Experimental and simulation results for input trajectories with high frequency contents

The main goal of this work was to obtain not too complex models allowing their use in HILS experiments. The developed models are reasonably accurate and the whole system can be simulated in real time with a thirdorder explicit solver with a fixed step size of $0.5 \mathrm{~ms}$. Closed-loop position control experiments were performed with the overall model running in a low-cost real-time card from dSPACE ${ }^{\circledR}$. The results were compared with the behaviour of the real system, with the comparison being very satisfactory.

\section{ACKNOWLEDGEMENT}

This work was funded by FCT under the programme POCTI.

\section{REFERENCES}

1 Edge, K. A. The control of fluid power systems - responding to the challenges. Proc. Instn Mech. Engrs, Part I: J. Systems and Control Engineering, 1997, 211(I2), 91-110.

I03504 (C) IMechE 2004
2 Burrows, C. R. Fluid power systems - an academic perspective. JHPS J. Fluid Power Systems, January 1998, 29(1), 26-32.

3 Lennevi, J., Palmberg, J. and Jansson, A. Simulation tool for the evaluation of control concepts for vehicle drive systems. In Proceedings of the 4th Scandinavian International Conference on Fluid Power, Tampere, Finland, September 1995.

4 Maclay, D. Simulation gets into the loop. Instn Electl Engrs Rev., May 1997, 109-112.

5 Otter, M. M., Schlegel, M. and Elmqvist, H. Modelling and realtime simulation of an automatic gearbox using Modelica. In Proceedings of the European Simulation Symposium (ESS '97), Passau, Germany, October 1997.

6 DS1102 DSP Controller Board, Technical Manuals (dSPACE gmbH, Paderborn).

7 Ferreira, J. A., Gomes de Almeida, F., Quintas, M. R. and Estima de Oliveira, J. P. Hybrid models for hardware-inthe-loop simulation of hydraulic systems. Part 1: theory. Proc. Instn Mech. Engrs, Part I: J. Systems and Control Engineering, 2004, 218(I0), 000-000.

8 Ferreira, J. A. Modelação de Sistemas Hidráulicos para Simulação com hardware-in-the-loop. $\mathrm{PhD}$ thesis, University of Aveiro, Aveiro, Portugal, 2003.

Proc. Instn Mech. Engrs Vol. 218 Part I: J. Systems and Control Engineering 
9 Gomes de Almeida, F. Model reference adaptive control of a two axes hydraulic manipulator. $\mathrm{PhD}$ thesis, University of Bath, Bath, 1993.

10 Simulink-Dynamic System Simulation for MATLAB, Technical Manuals.

11 Yu, J., Chen, Z. and Lu, Y. The variation of oil effective bulk modulus with pressure in hydraulic systems. Trans. ASME, J. Dynamic Systems, Measmt Control, March 1994, 116, 146-149.
12 MATLAB - The Language of Technical Computing, Technical Manuals.

13 Coleman, T., Branch, M. A. and Grace, A. Optimization Toolbox, 1999 (The Math Works, Inc., Nanch, Massachusetts).

14 Beater, P. Hylib - Library of Hydraulic Components for Use with Dymola, 2001 (Dynasim AB, Sweden). 